\title{
Development of the wing bones in quail's embryo; Coturnix japonica
}

\author{
H.K. Zorab ${ }^{1} \odot$ and K.A. Salih ${ }^{2} \odot$ \\ ${ }^{1}$ Department of Anatomy and Histology, College of Veterinary Medicine, University of Sulaymani, Sulaymani, \\ ${ }^{2}$ Department of Anatomy and Histology, College of Veterinary Medicine, University of Kirkuk, Kirkuk, Iraq
}

\begin{tabular}{l} 
Article information \\
\hline Article history: \\
Received December 27, 2019 \\
Accepted February 07, 2020 \\
Available online November 1, 2020 \\
\hline Keywords: \\
Chondrification \\
Double staining \\
Japanese quail embryo \\
Ossification center \\
\\
\hline Correspondence: \\
H.K. Zorab \\
hadia.zorab@ univsul.edu.iq
\end{tabular}

\begin{abstract}
Quail is an essential model in avian research because of economic importance in poultry industries around the world. Furthermore, its use in the experimental embryology research field. Therefore, this study aimed to identify the onset of chondrification and ossification of the wing bones also to summarize the main histological sequences related to the formation of the humerus in Japanese quail. Six embryos were taken every $24 \mathrm{hrs}$ from 3-16 days of incubation. Three embryos were prepared and stained with Alcian blue and Alizarin red for cartilage and bone, respectively. The other three embryos have been processed for histological examination. The macroscopical findings showed that the humerus, radius, ulna, coracoid, scapula, third, and fourth metacarpals were chondrified on $5^{\text {th }}$ day. However, first signs of ossification were observed in the humerus, radius, and ulna on $8^{\text {th }}$ day. While the minor digit remained none ossified at prehatching. The microscopical stages of developing humerus associated with the limb bud, apical ectodermal ridge formation, and chondrocyte differentiation on $3^{\text {rd }}, 4^{\text {th }}$, and $5^{\text {th }}$ day, respectively. The cartilage template of the humerus was established on $6^{\text {th }}$ day. The diaphysis and epiphyses of the humerus were formed on $7^{\text {th }}$ and $8^{\text {th }}$ day, correspondingly. The periosteal-bone collar was formed on $8^{\text {th }}$ day, and vascularization of chondroepiphysis has occurred on $9^{\text {th }}$ day. There was a difference in the timing of chondrification and ossification in the forelimb skeleton and humerus developed by the endochondral mechanism. The obtained results should be considered in teratological and molecular studies in skeletogenesis.
\end{abstract}

DOI: 10.33899/ijvs.2020.126438.1324, (C2021, College of Veterinary Medicine, University of Mosul.

This is an open access article under the CC BY 4.0 license (http://creativecommons.org/licenses/by/4.0/).

\section{Introduction}

Coturnix japonica is one of the order Galliformes and the family Phasianidae. It is calm, adaptable, and economical to maintain $(1,2)$. Japanese quail has assumed importance as an experimental model because of its distinct properties involving precocity of the species, fast and more productivity, early sexual maturity, short generation interval, and less feed and space requirements (3).

Osteogenesis occurs by two different mechanisms, intramembranous and endochondral ossification. Intramembranous ossification is a process responsible for the formation of the clavicle, and flat bones of the cranial vault. It is also a crucial process during the natural healing of bone fractures. During intramembranous ossification, the mesenchymal cells directly differentiate into osteoblasts without the formation of the cartilage model $(4,5)$. The long bones form and grow through endochondral ossification. Formation of the cartilage template is the initial stage of the endochondral mechanism, and it is made by aggregation of mesenchymal stem cells, follow they are transforming into chondrocytes. The cartilage model, once formed chondrocytes in the central region, undergoes more maturation to hypertrophic chondrocytes. These central hypertrophied chondrocytes undertake programmed cell death, and the matrix of the cartilage template is resorbed. The periosteal bud invaded the resorbed cartilage matrix at the center of the diaphysis and then invaded at both 
epiphyses by osteogenic and hematopoietic precursor cells that make the primary and secondary centers of ossification, correspondingly. These centers of bone formation gradually invade the intact cartilage; eventually, the cartilage template entirely replaced by bone, and only the articular surface remained cartilaginous $(6,7)$.

The prehatching development of the avian skeletal system has been commonly inspected. However, the histomorphological investigation on the prehatching development of the quail skeleton is limited. Therefore, this study aimed to determine the chondrification and ossification timing in the wing bones and to describe the histological stages of formation of the humerus in Japanese quail embryo.

\section{Materials and methods}

\section{Birds and housing}

A total of twenty healthy Coturnix japonica quail of both sexes aged three months were accommodated at the animal house, College of Veterinary Medicine, University of Sulaymani. The ratio of male to female was 1:3. The artificial photoperiod was $16 \mathrm{hrs}$, and the temperature maintained at $65-70^{\circ} \mathrm{F}$. The collected eggs were stored at $15^{\circ} \mathrm{C}$ for one week.

\section{Experimental design}

Eighty-four fertilized eggs weigh 10-12g, were incubated in the automatic egg turner incubator. The relative humidity and temperature of the egg incubator were adapted to 55$60 \%$, and $37.5 \pm 0.5^{\circ} \mathrm{C}$ respectively. Six embryos were taken at $24 \mathrm{hrs}$ interval from 3-16 days of incubation. Three embryos were prepared for double staining, and the other three embryos processed for histological examination.

\section{Preparation of embryo}

The eggs were cracked at the blunt end. The embryos removed from eggshells and separated from surrounding yolk and extraembryonic membranes. The internal organs were removed.

\section{Double staining}

The prepared embryos stained with Alcian Blue 8GX (C.I.74240 Merk, Germany) and Alizarin Red-S9 (C.I.58005 Merk, Germany) for cartilage and bone, respectively. The double staining steps were carried out according to $(8,9)$ with some modifications as follows; the skin and subcutaneous fat tissue have been removed carefully. This step was assisted by put the embryos in absolute ethanol or in hot water $\left(50^{\circ} \mathrm{C}\right)$ for a few minutes. This step at the early stages of embryonic development (with aged between $3^{\text {rd }}-5^{\text {th }}$ day) did not require. The embryos with aged between $3^{\text {rd }}-9^{\text {th }}$ day were fixed in absolute ethanol for 3 days, while embryos with aged between $10^{\text {th }}-16^{\text {th }}$ day were fixed for 7 days. Then, specimens were stained at $37-40^{\circ} \mathrm{C}$ for 4 days in a staining solution of $(0.3 \%$ (300 mg) Alcian blue in $70 \%$ ethanol (100 $\mathrm{ml}), 0.1 \%(100 \mathrm{mg})$ Alizarin red in $99 \%$ ethanol $(100 \mathrm{ml})$, glacial acetic acid $(100 \mathrm{ml})$, and $70 \%$ ethanol $(1500 \mathrm{ml})$. The stained specimens were bathed for 2 hrs in changed water, and they macerated in an aqueous solution of potassium hydroxide as follows: embryos with aged between $3^{\text {rd }}-5^{\text {th }}$ day macerated in $0.5 \% \mathrm{KOH}$ for $15 \mathrm{~min}$, embryos with aged between $6^{\text {th }}-8^{\text {th }}$ day in $0.5 \% \mathrm{KOH}$ for 30 min, embryos with aged between $9^{\text {th }}-11^{\text {th }}$ day in $1 \% \mathrm{KOH}$ for $15 \mathrm{hrs}$, embryos with aged $12^{\text {th }}-14^{\text {th }}$ day in $1.5 \% \mathrm{KOH}$ for $20 \mathrm{hrs}$, and embryos with aged $15^{\text {th }}-16^{\text {th }}$ day in $2 \% \mathrm{KOH}$ for $24 \mathrm{hrs}$. Then, specimens cleared by an aqueous solution of gradually increasing concentration of glycerol $20 \%, 50 \%$, and $80 \%$ for 3 days for each concentration. Lastly, embryos stored in a pure glycerol $100 \%$. For permanent storage, kept embryos at $4^{\circ} \mathrm{C}$, and few thymol crystals, have been added to inhibit fungus growth and putrefaction.

\section{Observation and measurement of the embryo}

The stained specimens put in a glass or transparent plastic dish filled with $100 \%$ glycerol carefully to allow the specimen to settle down entirely. Observation of the skeletal elements was performed under a stereomicroscope (Optica, BG-Italy), and the embryos positioned laterally to expose the wing elements. The total length and the length of the ossified part of the humerus have been measured by using an ocular micrometer under dissecting microscope (x20) from 5-16 days of incubation. The number of cases was three embryos per day. Statistical analysis was performed by SPSS version 22 (SSPS Inc., USA). The data were expressed as mean \pm SD (Standard Deviation). The calibration factor was (0.058) calculated as follows; 1 Stage division $=0.01 \mathrm{~mm} » 100$ Stage divisions $=100 * 0.01=1 \mathrm{~mm} ;$ Stage divisions $/$ Ocular divisions $=1 \mathrm{~mm} / 17=0.058 \mathrm{~mm}$.

\section{Histological examination}

The prepared embryos were fixed in $10 \%$ neutral buffered formalin for $24 \mathrm{hrs}$. Tissues obtained for histological examination included the humerus, processed by routine histological processing method; sections $(5 \mu \mathrm{m}$ thickness) were taken and stained with hematoxylin and eosin, Alizarin red, modified von Kossa, and Masson's trichrome stains then examined by light microscope (Motic, China). The presented images were captured by using a digital camera (Am scope, China).

\section{Results}

\section{Macroscopical findings}

In the present study, the onset of chondrification and ossification of the forelimb elements of the Japanese quail embryo identified by using Alcian blue and Alizarin red, respectively. The cartilaginous parts stained blue with Alcian blue while the ossified regions were stained red with Alizarin red, as shown in (Figures 1 and 2). $3^{\text {rd }}$ day of incubation: The limb buds were evident as slightly thickened ridges at 
laterally about midway down of the body. $4^{\text {th }}$ day of incubation: The limb buds more detectable and protruded from the embryo body. $5^{\text {th }}$ day of incubation: The chondrification of the coracoid, scapula, humerus, radius, ulna, third, and fourth metacarpals were observed as slightly blue-stained. $6^{\text {th }}$ day of incubation: The chondrification process followed by chondrification of the Os carpi radiale,
Os carpi ulnare, the second metacarpal and first phalanxes of the major and minor digits. $7^{\text {th }}$ days of incubation: The second phalanx of the major digit was blue stained. $8^{\text {th }}$ day of incubation: The humerus, ulna, and radius were started ossification. The ossified part was visualized as the small stained red center at the diaphysis. The first phalanx of the alular digit was blue stained.
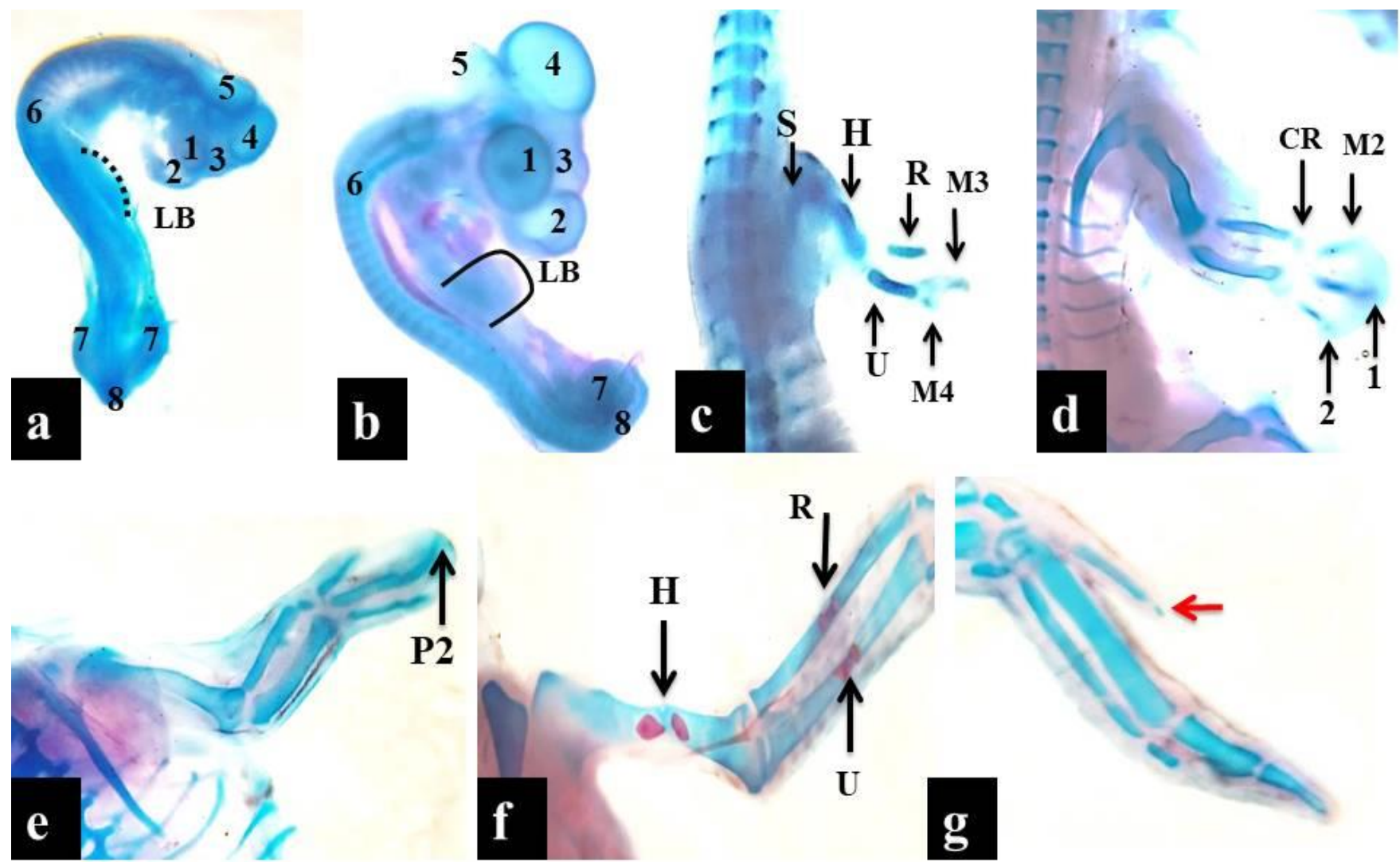

Figure 1: Japanese quail embryo: a. Small ridge of upper limb bud LB, ( $3^{\text {rd }}$ day), b. Protruded limb bud LB, (4 $4^{\text {th }}$ day), in (a and b) 1. Eye, 2. Telencephalon, 3. Diencephalon, 4. Mesencephalon, 5. Metencephalon, 6. Spinal cord, 7. Lower limb bud, 8. Tail bud, c. Chondrification of scapula S, humerus $\mathrm{H}$, radius R, ulna U, third metacarpal M3, fourth metacarpal M4 (5 ${ }^{\text {th }}$ day), d. Chondrification of Os carpi radiale CR, second metacarpal M2, the first phalanx of major digit 1, the first phalanx of minor digit 2 ( $6^{\text {th }}$ day), e. Chondrification of the second phalanx of major digit P2 ( $7^{\text {th }}$ day), $f$ and g. Ossification center (black arrows) of the humerus $\mathrm{H}$, radius $\mathrm{R}$, and ulna $\mathrm{U}$, chondrification of the first phalanx of the alular digit (red arrow), ( $8^{\text {th }}$ day). (Double staining, $\mathrm{x} 20)$.

$9^{\text {th }}$ day of incubation: The clavicles, coracoid, scapula, $3^{\text {rd }}$, and $4^{\text {th }}$ metacarpals were ossified. $2^{\text {nd }}$ phalanx of the alular digit was blue stained. The proximal extremity of the second metacarpal combined with the articular surface of the third metacarpal. $10^{\text {th }}$ day of incubation: The carpi fused with metacarpi to form a carpometacarpal compound. The entire pectoral girdle and wing elements formed, and the ossification part extended through the extremities of the elements. $11^{\text {th }}$ day of incubation: The first phalanx of the major digit was ossified and red-stained. $12^{\text {th }}$ day of incubation: The second phalanx of the major digit and the first phalanx of alular digits were turned red at the central portion. $13^{\text {th }}$ day of incubation: The earlier ossified parts of the wing skeleton extended without any new ossification center. $14^{\text {th }}$ day of incubation: The second phalanx of the alular digit was ossified. $15^{\text {th }}-16^{\text {th }}$ day of incubation: Through $15^{\text {th }}$ and $16^{\text {th }}$ day of the prehatching period, no ossification was occurred in the first phalanx of the minor digit, extremities of the long bones, the distal end of the scapula, and carpal elements which were remained cartilaginous as indicated by blue stained. Finally, on 17 days, the chick of Coturnix japonica hatched. 


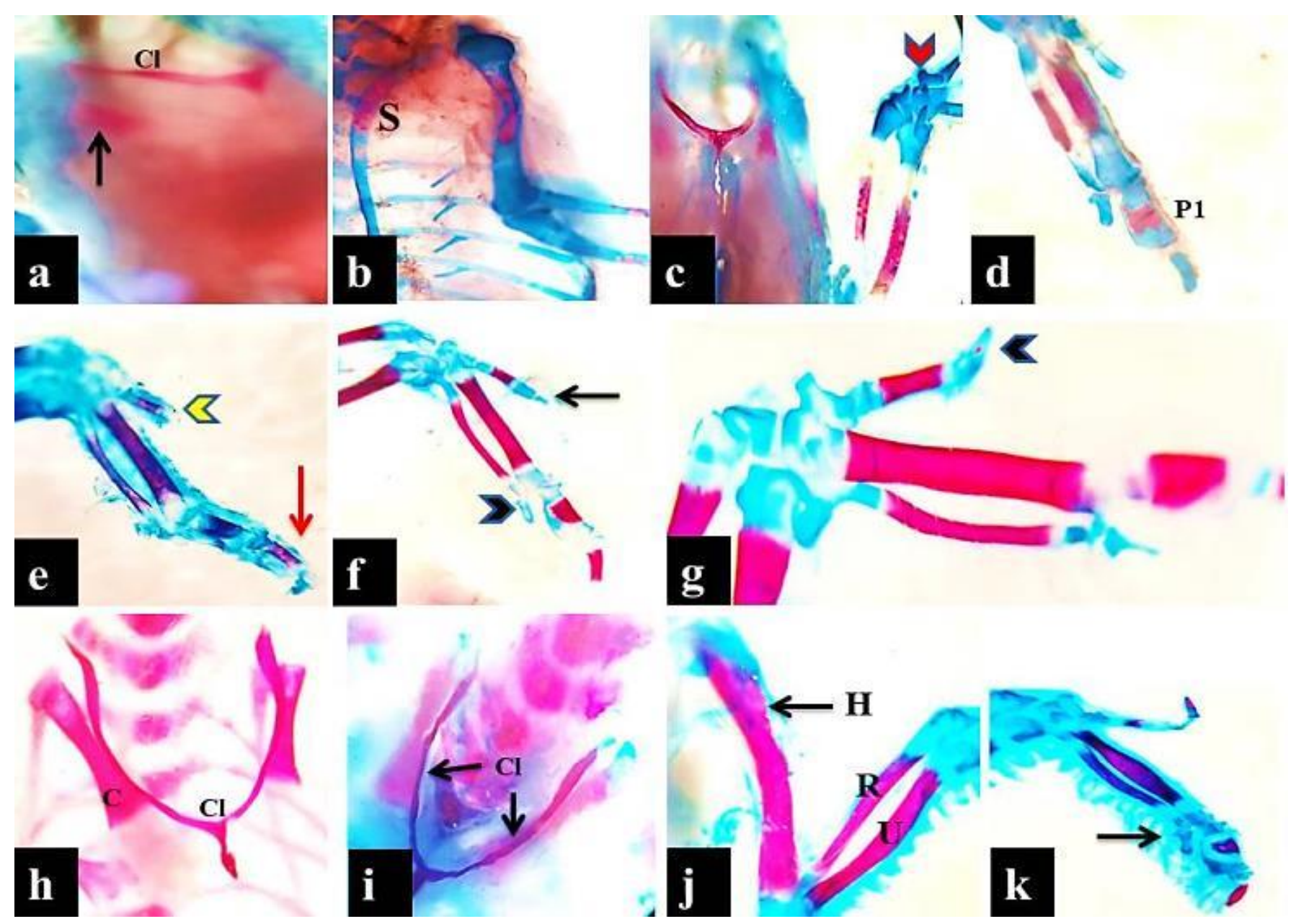

Figure 2: a and b. Chondrification of clavicles $\mathrm{Cl}$, coracoid (black arrow), scapula $\mathrm{S}$, (9 $9^{\text {th }}$ day), c. Carpometacarpal compound (red head arrow), (10 $0^{\text {th }}$ day), d. Ossification of the first phalanx of major digit P1, (1 $1^{\text {th }}$ day), e. Ossification of the first phalanx of alular digit (yellow head arrow) and the second phalanx of major digit (red arrow), (12 ${ }^{\text {th }}$ day), $\mathrm{f}$. The second phalanx of alular digit (black arrow) and minor digit (black head arrow) remained non-ossified (13 ${ }^{\text {th }}$ day), g. Ossification of the second phalanx of alular digit (black head arrow) (14 ${ }^{\text {th }}$ day), h. Clavicles $\mathrm{Cl}$, Coracoid C, $\left(15^{\text {th }}\right.$ day), i. Clavicles $\mathrm{Cl}$, j. Humerus H, Radius R, Ulna U, k. Only the minor digit remained cartilaginous (black arrow), $i, j$ and $k$ (16 ${ }^{\text {th }}$ day). (Double staining, $\left.x 20\right)$. Note: In figures ( $\mathrm{d}$ and $\mathrm{e}$ ) the second phalanx of the alular digit lost during imaging.

The result of statistical analysis revealed that there was a significant increase at $\mathrm{P}<0.05$ in the total length and length of the ossified part of the diaphysis of the developing humerus among studied days from $5^{\text {th }}-16^{\text {th }}$ day of incubation, particularly there was a noticeable increase in the total length of the humerus on $8^{\text {th }}$ day (Figure 3 ).

\section{Microscopical findings}

The histological examination of the embryo on $3^{\text {rd }}$ day showed a lateral swelling from the body wall known as limb bud. The limb bud composed of undifferentiated mesenchymal cells surrounded by ectodermal cells layer (Figure 4a). The ectodermal cells layer increased in number and became thickening termed the apical ectodermal ridge (AER) on $4^{\text {th }}$ day, which was covered the distal surface of the limb bud (Figures $4 \mathrm{~b}$ and $\mathrm{c}$ ). On $5^{\text {th }}$ day there was an aggregation of mesenchymal cells in the limb bud known as mesenchymal condensation. This condensation has appeared as a small round area consisted of undifferentiated mesenchymal cells. Some of the mesenchymal cells in the center of the condensation region, differentiated into round chondrocytes (Figure 4d), whereas mesenchymal cells at the periphery of the condensation synthesized the prospective perichondrium and demarcated the humerus from adjacent mesenchymal tissues. The cartilage template was formed on 6 days, and it consisted of small chondrocytes and surrounded by undeveloped perichondrium (Figure 4e). 


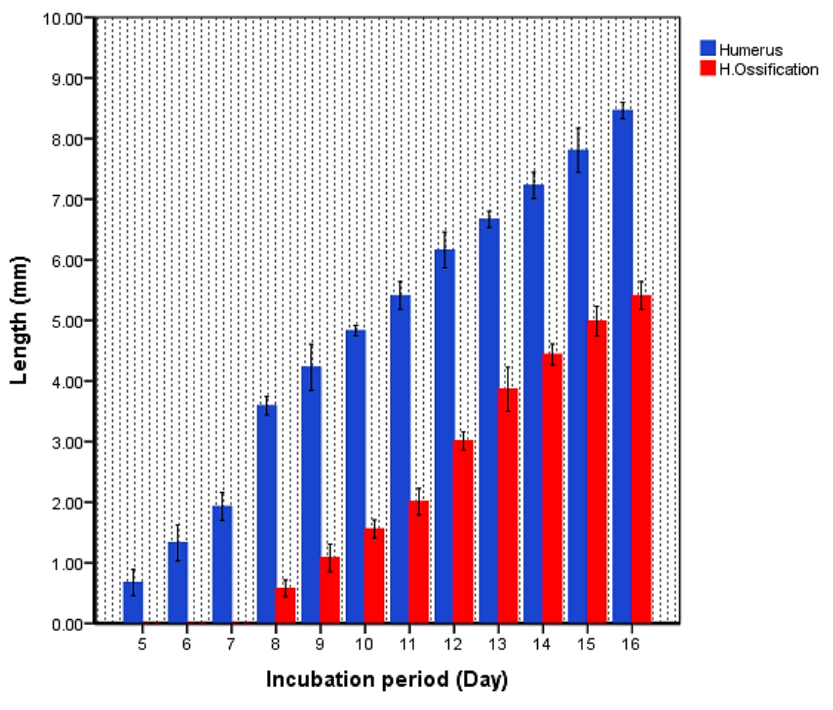

Figure 3: The graph showing the significant difference in the total length (blue color bars) and the length of the ossified part (red color bars) of the humerus for three embryos per day from 5-16 days of incubation, the data presented as $($ Mean $\pm \mathrm{SD}$ ) at $\mathrm{P}<0.05$.

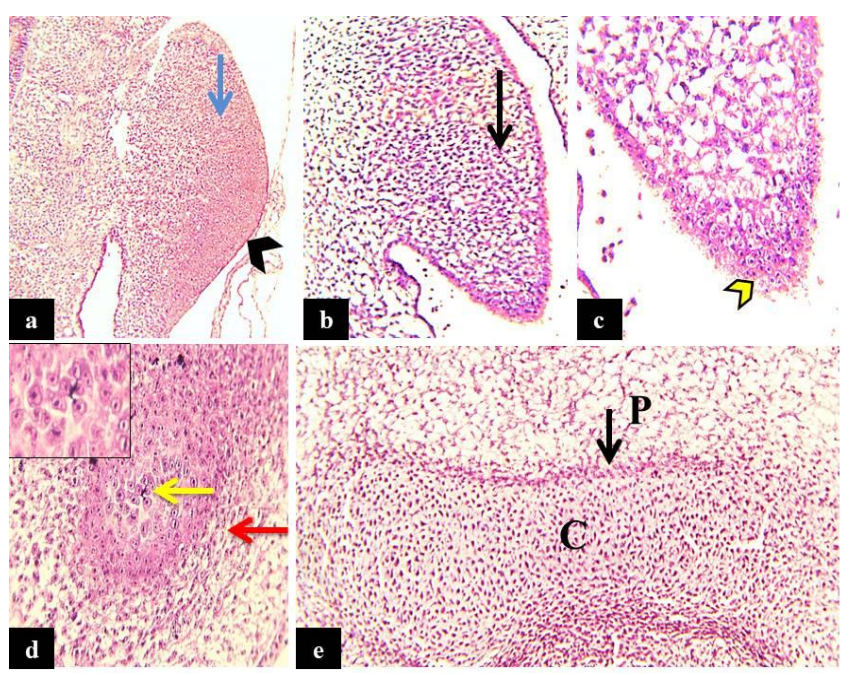

Figure 4: Microscopical sections of the embryo showed: a. Limb bud (blue arrow), ectoderm layer (black head arrow), ( ${ }^{\text {rrd }}$ day), b. Elongated limb bud (black arrow), c. Apical ectodermal ridge (yellow head arrow), ( $4^{\text {th }}$ day), d. Round chondrocytes (yellow arrow) and specified by inset in the center of mesenchymal condensation, prospective perichondrium (red arrow), ( $5^{\text {th }}$ day), e. Cartilage template $\mathrm{C}$, prospective perichondrium $\mathrm{P},\left(6^{\text {th }}\right.$ day $) . \mathrm{H} \& \mathrm{E}$ stain, $(\mathrm{a}, \mathrm{b})$ $\mathrm{x} 100,(\mathrm{c}, \mathrm{d}, \mathrm{e}) \mathrm{x} 400$.

The diaphysis of the cartilage template was established on $7^{\text {th }}$ day, and surrounded by developed perichondrium, including an inner cellular layer and outer fibrous layer
(Figures 5a and b). The cartilage template attained the shape of the prospective humerus on $8^{\text {th }}$ day; it consisted of middiaphysis and epiphyses at the ends (Figure 5c). Chondrocytes at the epiphyseal area were small rounded to oval shape and randomly distributed throughout the extracellular matrix. While chondrocytes in the center of the diaphysis were organized into a hypertrophic zone of large chondrocytes (Figure 5d), and on both peripheries of the hypertrophic zone there was a proliferative zone of flattened shape chondrocytes (Figure 5e).
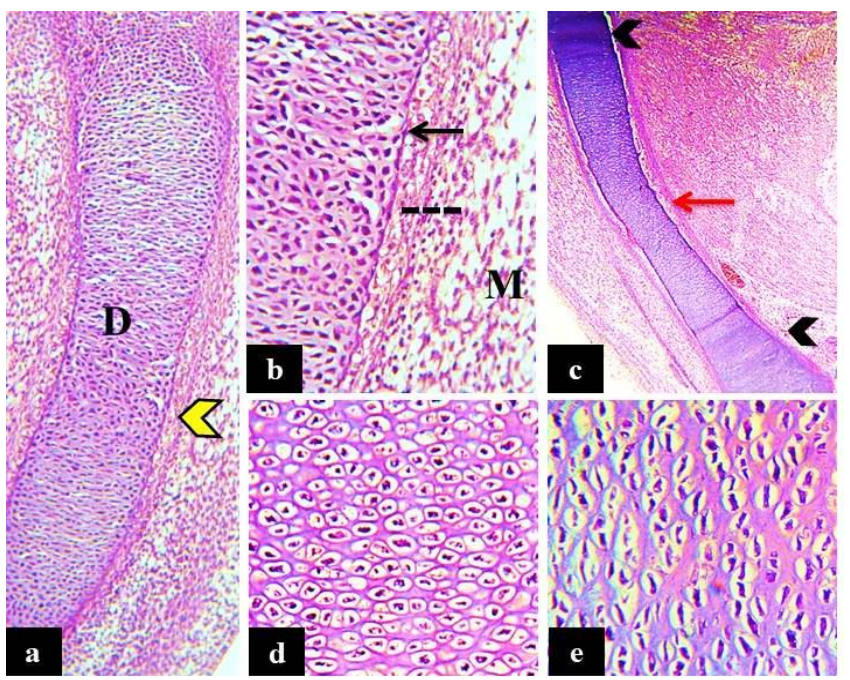

Figure 5: Microscopical sections of the humerus showed: a. The diaphysis $\mathrm{D}$ of the cartilage template, perichondrium (yellow head arrow), b. Inner cellular layer (black arrow) and outer fibrous layer (dash line) of the perichondrium, undifferentiated mesenchymal cells $\mathrm{M},\left(^{\text {th }}\right.$ day), c. Epiphyses (black head arrows), diaphysis (red arrow), d. Hypertrophied zone, e. Proliferative zone ( $8^{\text {th }}$ day), H\&E stain, (a) x100, (c) x40, (b, d, e) x400.

The differentiation of the inner cellular layer of perichondrium into osteoblasts occurred on $8^{\text {th }}$ day. These osteoblasts deposited osteoid tissue as a bone collar around the mid-diaphysis at the site of the hypertrophied chondrocytes and perichondrium transformed into the periosteum (Figure 6a). Calcification of the bone collar was occurred on the same day as indicated by red and blackbrown stained with Alizarin red and modified von Kossa stain, respectively (Figures $6 \mathrm{~b}$ and $\mathrm{c}$ ).

On $9^{\text {th }}$ day, the second layer of bone collar deposited and accompanied by vascular and cellular penetration into hypertrophied chondrocytes on the periphery of the middiaphysis of the cartilage template (Figure 6d). Furthermore, vascularization of the chondroepiphysis was firstly observed. The proximal epiphysis of the humerus revealed a small, short unbranched canal introduced from the perichondrium known as epiphyseal cartilage canal on $9^{\text {th }}$ day (Figure 6e). 
The periosteal bud conveyed hemopoietic cells and osteoprogenitor cells into the space left after resorption of the cartilage matrix, and the medullary cavity formed on $10^{\text {th }}$ day (Figure 6f). The periosteal bone collar more deposited by osteoblasts around mid-diaphysis and the thickness of it increased toward the center of the diaphysis on $11^{\text {th }}$ day (Figure $6 \mathrm{~g}$ ). The endochondral ossification started when the osteoblasts used the cartilage matrix as a scaffold and began to secrete osteoid tissue and bone spicules formed. In turn, these spicules connected and bone trabeculae formed on $12^{\text {th }}$ day (Figure 6h). Mature osteoblasts embedded in the matrix and transformed into osteocytes; thus, the primary woven bone formed on $13^{\text {th }}$ day (Figure 6i).

Calcification of the trabecular bone has occurred on $14^{\text {th }}$ day, as indicated by the positive reaction to von Kossa satin
(Figure $6 \mathrm{j}$ ). On $15^{\text {th }}$ day the endochondral bone trabeculae more synthesized till emerged with the periosteal bone collar and they were occupied all mid-diaphysis of the humerus and constituted the primary ossification center POC (Figure 6k). The bone trabeculae were intensively mineralized and deeply stained with Alizarin red stain (Figure 61).

The osteoclasts digested the endochondral trabecular bone in resorption bay (Figure 7a) and bone marrow cavity within mid-diaphysis started to form on $16^{\text {th }}$ day (Figures $7 \mathrm{~b}$ and c). The histological section from the distal epiphysis of the developing humerus showed cartilage canals without the presence of the secondary ossification center (Figures 7d, e and $\mathrm{f}$ ).

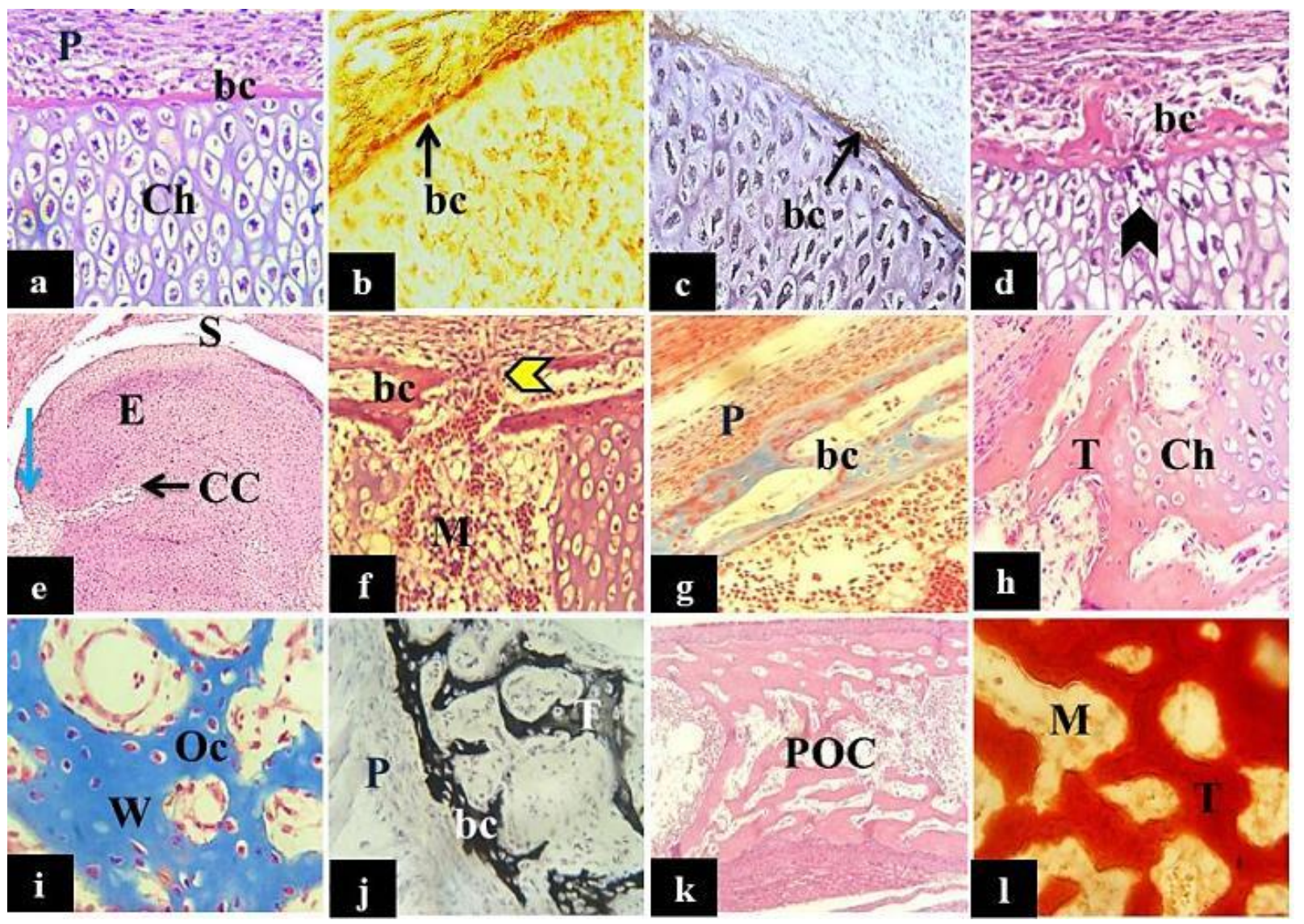

Figure 6: a. Formation of bone collar bc above hypertrophied chondrocytes $\mathrm{Ch}$, periosteum $\mathrm{P}, \mathrm{b}$. The red color of calcium deposits of the bone collar bc with Alizarin red, c. Brown-black color of calcium deposits of the bone collar bc with modified von Kossa, ( $8^{\text {th }}$ day), d. Periosteal bud invasion (black head arrow) from bone collar bc, e. Cartilage canal CC, proximal epiphysis E, perichondrium (blue arrow), shoulder joint $\mathrm{S},\left(9^{\text {th }}\right.$ day), f. Medullary cavity $\mathrm{M}$, cellular and vascular invasion as an irruption canal (yellow head arrow), bone collar bc, $\left(10^{\text {th }}\right.$ day), g. Bone collar bc more deposited, and red color indicated the mineralized portion of the bone collar while blue color indicated collagen fiber of it, periosteum $\mathrm{P}\left(11^{\text {th }}\right.$ day), h. Chondrocytes Ch underwent endochondral ossification and they replaced by trabecular bone $\mathrm{T}\left(12^{\text {th }}\right.$ day), i. Primary woven $\mathrm{W}$ bone, embedded osteocytes Oc $\left(13^{\text {th }}\right.$ day), j. Calcified trabecular bone T, bone collar bc, periosteum P $\left(14^{\text {th }}\right.$ day $)$, k. Primary ossification center POC, 1. Mineralized trabecular bone T, medullary space M, (15 th day). (a, d, e, f, h, k) H\&E, (b, l) Alizarin red, (c, j) von Kossa, (g, i) Masson's Trichrome, (a, b, c, d, f, g, h, i, j, l) x400, (e, k) x100. 


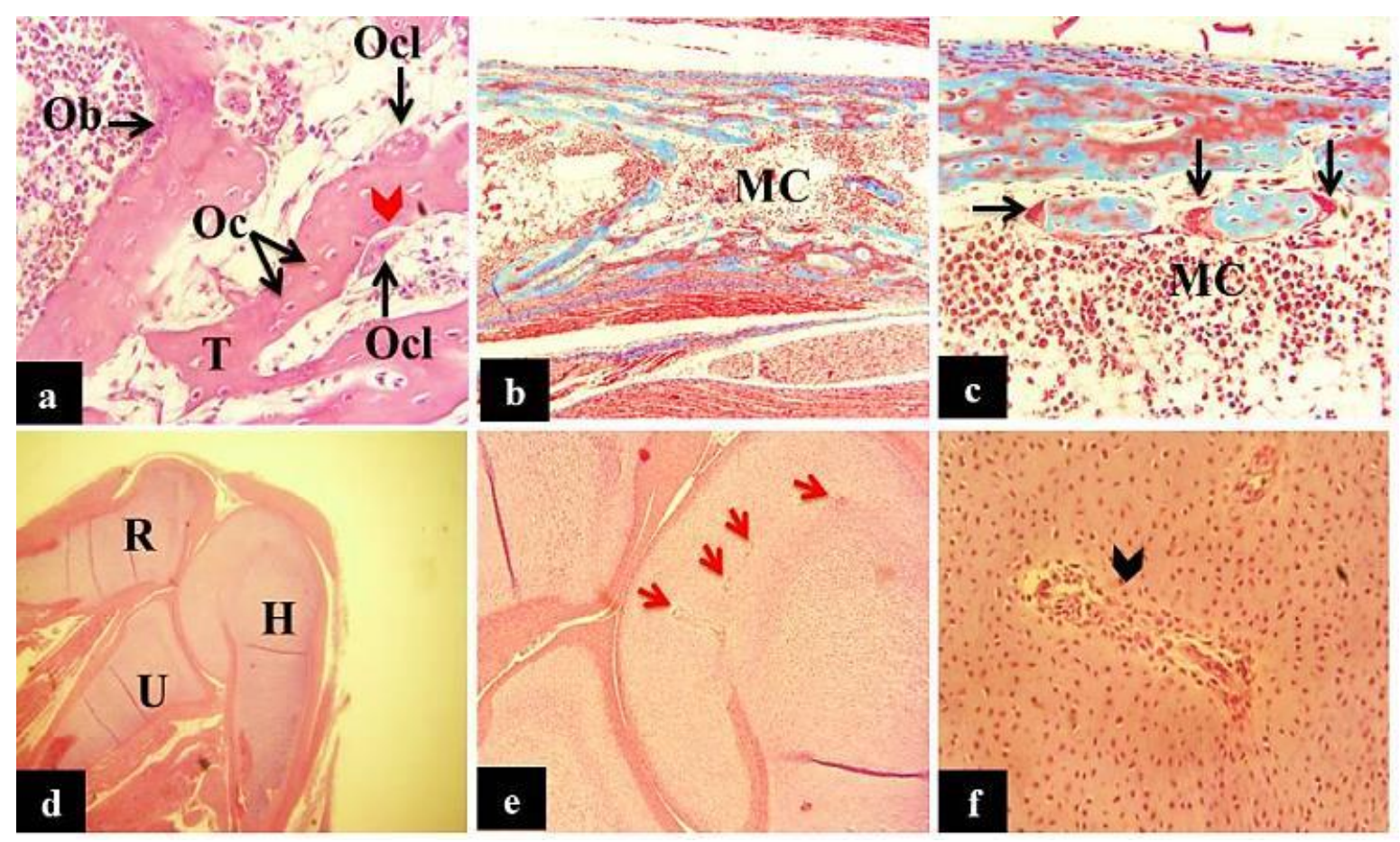

Figure 7: a. The multi-nucleated osteoclasts Ocl in resorption bay (red head arrow) digested bone trabeculae T, entrapped osteocytes $\mathrm{Oc}$, osteoblasts $\mathrm{Ob}$ on the free surface of bone trabeculae, b. Bone marrow cavity MC, c. Small bone trabeculae at mid- diaphysis digesting by osteoclasts (black arrows), bone marrow cavity MC, d. Humerus $\mathrm{H}$, radius R, and ulna $\mathrm{U}$ at the elbow joint, e. Numerous small and short cartilage canals (red arrows) within epiphysis of the humerus $\mathrm{H}$ without secondary ossification center, f. Higher magnification from section (e) showed cartilage canal (arrow head) with definitive outline and contain loose connective tissue within chondroepiphysis, $16^{\text {th }}$ day, (a, d, e, f) H\&E stain, (b, c) Masson's Trichrome, (a, c, f) x400, (b, e) x100, (d) x40.

\section{Discussion}

Quail is not only an agricultural bird but also is one of the ideal vertebrate models used to study a variety of investigations (10). More recently, in third countries, this species has been housed as an alternative source of animal protein $(11,12)$. There is much study regarding the prehatching skeletal development of Galliformes, and many authors did research concerning quail such as (13-15). The purpose of this study was to determine the onset of chondrification and ossification of the forelimb bones in the Japanese quail embryo.

This study on $3^{\text {rd }}$ day showed that forelimb region has appeared as a lateral ridge known as limb bud. The first occurrence of chondrification was observed in the scapula, coracoid, humerus, radius, ulna, second, and third metacarpal bones on $5^{\text {th }}$ day. In a previous study (14) in Japanese quail, the chondrification of the humerus, radius, and ulna recorded much earlier on $4^{\text {th }}$ day. More recently (13) in Chinese quail, the chondrification of the humerus documented on $4^{\text {th }}$ day, and chondrification of the scapula, coracoid, radius, ulna, second, and third metacarpal bones recorded on $5^{\text {th }}$ day. The first sign of ossification was observed at the center of the diaphysis of the humerus, ulna, and radius on $8^{\text {th }}$ day. The ossified part appeared as a redstained center. In the past, the early ossification center of these bones on $7^{\text {th }}$ day stated by (14). On the other side (15) reported a remarkable earlier of the ossification of these bones on $6^{\text {th }}$ day. Statistically, the data showed that the length of chondrified and ossified parts of the humerus significantly increased particularly; there was a remarkable increase in the length of the cartilage part of the humerus on day 8 .

The thin $U$ shaped clavicles were ossified directly by intramembranous mechanism on 9 day, whereas (15) and (14) reported the intramembranous ossification of clavicles on $7^{\text {th }}$ and $8^{\text {th }}$ day, respectively. The attained result showed that the first phalanx of minor digit remained cartilaginous at prehatching in contrast (15) documented the ossification of this phalanx on $14^{\text {th }}$ day and (14) on $16^{\text {th }}$ day. In Chinese quail, the ossification of this digit stated on $14^{\text {th }}$ day (13).

In the current study, variations in the developmental timing of the wing skeleton with other studies have been stated. Variations in these results are probably related to strain, health, age, nutrition, management, and photoperiod 
of breeder flock. Size, weight, quality, standardized collection, transportation, and storage of eggs, factors associated with the incubation procedure such as temperature, relative humidity, the time taken for the embryo to warm to the incubation temperature, and turning per day could be considered as factors that contributed these differences.

In the mammals and birds, most bones are made by endochondral ossification, in which an essential cartilage template is formed and gradually replaced by bones (7). Microscopically on $3^{\text {rd }}$ day the limb bud composed of undifferentiated mesenchymal cells surrounded externally by ectoderm layer. On 4 day, the ectodermal cells became thick, and the apical ectodermal ridge was established (AER). The (AER), allowing the limb bud to grow by preserves the underlying mesenchymal cells in a proliferative state (16). On $5^{\text {th }}$ day, a group of cells in the mid-point of the mesenchymal condensation area differentiated into chondrocytes. Transcription factor Sox-9 is considered as a major regulator of mesenchymal cell aggregation and differentiation of chondrocyte (17).

On $6^{\text {th }}$ day, the cartilage template was formed; this cartilage template is growth by two main mechanisms; interstitial growth which is responsible for elongation of cartilage template by the mitotic activity of chondrocytes, while appositional growth lead to the increasing thickness of template by addition of cartilage matrix by chondroblasts in the inner cellular layer of the perichondrium (18). The chondrocytes within the diaphysis were arranged into central hypertrophic and peripheral proliferative zones on day 8 . Collagen type $\mathrm{X}$ is the most specific marker of hypertrophic chondrocytes (19). Indian hedgehog (Ihh) is a major factor which regulates bone development expressed by prehypertrophic chondrocytes (chondrocytes leaving the proliferative zone) that keeps chondrocyte in proliferation state and inhibits hypertrophy of chondrocyte. The chondrocyte proliferation is reliant on the Ihh induction by expression of the parathyroid hormone-related peptide (PTHrP) (20). PTHrP is expressed by chondroblasts and early proliferating chondrocyte. In addition, Ihh in endochondral bone formation plays a direct role in enhancing osteoblast differentiation in the perichondrium, also affects vascular and cellular invasion into cartilage template which, occurs at the next stage of bone formation (7). Runx2, which is expressed highly by mature and hypertrophic chondrocytes induces chondrocyte hypertrophy and succeeding bone formation in cartilage (21). The hypertrophic chondrocytes undergo physiological cell death or survive and dedifferentiated into osteoblasts (19).

In the present study, cells in the inner layer of the perichondrium differentiated into osteoblasts, and they formed a thin layer of bone around the mid-diaphysis of the cartilage model named periosteal collar bone on $8^{\text {th }}$ day. This bone collar considered the first hallmark of endochondral ossification in long bones (22). Positive reaction to Alizarin red and von Kossa satin (Figures $6 \mathrm{~b}$ and $\mathrm{c}$ ) on $8^{\text {th }}$ day confirmed that the red-color of double staining in the middiaphysis of the humerus (Figure 1f), it means the onset of ossification. On day 9, the second layer of bone collar deposited by osteoblasts. Concomitantly periosteal bud invasion of the cartilage template started. These findings substantially were comparable with (23). In the current study, resorption of the cartilage matrix began when a small cavity became evident and occupied by undifferentiated cells originated from the periosteum. In mammals, hyaline cartilage is first calcified and then resorbed, but in the embryos of birds, cartilage resorption is independent of calcification (20). The cartilage canal penetrated the proximal epiphysis of the humerus on $9^{\text {th }}$ day. The cartilage canal is present in human, mammalian, and some avian species. It has similar structural characteristics among vertebrates. In the chicken femur, cartilage canals contain arterioles, venules, capillaries, and mesenchymal cells, which are embedded in the canal matrix. In the bird, they form at prehatching; however, in murine, the cartilage canals are found after birth (24). The cartilage canals are significant for the nourishment of the developing cartilage and removal of waste materials. In addition, they are vital for the creation of the secondary ossification center, normal epiphyseal development and establishment of the growth plate (25).

\section{Conclusion}

There are differences in the timing of bone development among quails. In Japanese quail, the chondrification and ossification for the first time found on $5^{\text {th }}$ and $8^{\text {th }}$ day of incubation, respectively. Intramembranous ossification of the furcula observed on $9^{\text {th }}$ day. The carpal bones and minor digit were remained none ossified at the prehatching period. The humerus as long bone developed by endochondral ossification and cartilage template was formed on $6^{\text {th }}$ day. The cartilage canals penetrated the epiphyses without the formation of a secondary ossification center at prehatching.

\section{Acknowledgments}

The authors would like to thank the College of Veterinary Medicine, University of Sulaymani, for providing the animal house and facilities during this research.

\section{Conflict of Interest}

The authors declare that there are no conflicts of interest regarding the publication of this manuscript.

\section{References}

1. Ainsworth SJ, Stanley RL, Evans DJ. Developmental stages of the

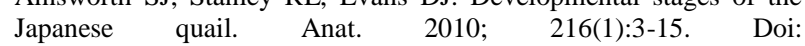
$\underline{10.1111 / \mathrm{j} .14697580 .2009 .01173 . \mathrm{x}}$ 
2. Nunes K, Garcia RG, Naas IA, Eyng C, Caldara FR, Sgavioli S, Roriz $\mathrm{BC}$, Ayala CM. Effect of LED lighting colors for laying Japanese quails. quails. Braz J Poultry Sci. 2016;18(SPE):51-56. Doi: 10.1590/1806-9061-2015-0176

3. Huss D, Poynter G, Lansford R. Japanese quail (Coturnix japonica) as a laboratory animal model. Lab Anim. 2008;37(11):513-519. Doi: 10.1038/laban1108-513

4. Karaplis AC. Embryonic development of bone and regulation of intramembranous and endochondral bone formation. In: John P, Bilezikian LG, Raize T, John M, editors. Principles of bone biology. New York: Elsevier press; 2008. 53-84 p. Doi: 10.1016/B978-0-12373884-4.00025-2

5. Provot S, Schipani E, Wu J, Kronenberg H. Development of the skeleton, In: Marcus R, Feldman D, Nelson D, Rosen CJ, editors. Osteoporo. New York: Elsevier press; 2013. 97-126 p. Doi: 10.1016/B978-0-12-415853-5.00006-6

6. Ibrahim SM, Handool KO, Abdul AA, Yusof SM, Ibrahimmi M, Yusof L. Histological evaluation of the possible role of $\mathrm{Na}+\mathrm{H}+$ entiporter and anion exchanger in endochondral ossification activities of secondary bone healing in rats. Iraqi J Vet Sci. 2020;34(2):233-240. Doi: 10.33899/ijvs.2019.125832.1165

7. Long F, Ornitz DM. Development of the endochondral skeleton. Cold Spring Har Perspect Biol. 2013;5:1-20. Doi: 10.1101/cshperspect.a008334

8. Miller, Doris M, Tarpley, John. An automated double staining procedure for bone and cartilage. Biotech Histochem. 1996;71(2):7983. Doi: $10.3109 / 10520299609117138$

9. Whitaker J, Dix, Kathleen M. Double staining technique for rat foetus skeletons in teratological studies. Lab Anim. 1979;13(4):309-310. Doi: $10.1258 / 002367779780943233$

10. Poynter G, Huss D, Lansford R. Japanese quail: an efficient animal model for the production of transgenic avians. Cold Spring Har Proto. 2009; 2009(1):1-6. Doi: 10.1101/pdb.emo112

11. El-Katcha M, Soltan M, Sheaita S, Naggar El, M El-Shobokshy SA. Growth Performance, Blood Biochemical Changes, Carcass Traits and Nutrient Digestibility of Growing Japanese Quail Fed on Various Dietary Protein and Calcium Levels. Alex J Vet Sci. 2015;44(1):38-53. Doi: $10.5455 /$ ajvs. 171987

12. Hameed HM, Tawfeek F, Adul-Rhaman S. Effect of $\beta$-mannanase, Lysolecithin and probiotic on some reproductive performance and hormone profile in female quail. Iraqi J Vet Sci. 2020;34(1): 87-93. Doi: 10.33899/ijvs.2019.125587.1097

13. Nakamura Y, Nakane Y, Tsudzuki M. Skeletal development in bluebreasted quail embryos. Anim Sci. 2019;90(3):353-365. Doi: 10.1111/asj.13159

14. Nakane Y, Tsudzuki M. Development of the skeleton in Japanese quail embryos. Dev Growth Differ. 1999;41(5):523-534. Doi: 10.1046/j.1440-169x.1999.00454.x

15. Pourlis AF, Antonopoulos J. The ossification of the pectoral girdle and wing skeleton of the quail (Coturnix Coturnix japonica). Anat Histolo Embryol. 2011;40(3):219-225. Doi: $\quad$ 10.1111/j.14390264.2011.01065.x

16. Petit F, Sears KE, Ahituv N. Limb development: a paradigm of gene regulation. Nat Rev Gene. 2017;18(4):245-534. Doi: 10.1038/nrg.2016.167

17. Ono N, Ono W, Nagasawa T, Kronenberg HM. A subset of chondrogenic cells provides early mesenchymal progenitors in growing bones. Nat Cell Biol. 2014;16(12):1157-1167. Doi: 10.1038/nrg.2016.167

18. Kini U, Nandeesh B. Physiology of bone formation, remodeling, and metabolism. In: Fogelman I, van der Wall H, editor. Radionuclide and hybrid bone imaging. Heidelberg: Springer press; 2012. 29-57 p. Doi: 10.1007/978-3-642-02400-9 2

19. Yang L, Tsang KY, Tang HC, Chan D, Cheah KS. Hypertrophic chondrocytes can become osteoblasts and osteocytes in endochondral bone formation. Proc Nat Acad Sci. 2014;111(33):12097-12102. Doi: 10.1073/pnas.1302703111

20. Mackie E, Ahmed YA, Tatarczuch L, Chean KS, Mirams M. Endochondral ossification: how cartilage is converted into bone in the developing skeleton. Int J Biochem Cell Biolo. 2008;40(1):46-62. Doi: 10.1016/j.biocel.2007.06.009

21. Wei X, Hu M, Mishina Y, Liu F. Developmental regulation of the growth plate and cranial synchondrosis. J Den Res. 2016;95(11):12211229. Doi: $10.1177 / 0022034516651823$

22. Shapiro F. Bone development and its relation to fracture repair. The role of mesenchymal osteoblasts and surface osteoblasts. Eur Cell Mater. 2008;1553-76. Doi: 10.22203/eCM.v015a05

23. Ahmed YA, Soliman, SA. Long bone development in the japanese quail. Pak J Biol Sci. (2013);16(18):911-919. Doi: 10.3923/pjbs.2013.911.919

24. Blumer MJF, Fritsch H, Pfaller K, Brenner E. Cartilage canals in the chicken embryo: Ultrastructure and function. Anat Embryolo. 2004;207(6):453-462. Doi: 10.1007/s00429-003-0363-0

25. Blumer MJF, Longato S, Fritsch H. Structure, formation and role of cartilage canals in the developing bone. Ann Anat. 2008;190(4):305315. Doi: 10.1016/j.aanat.2008.02.004

\section{تطور عظام الجناح في جنين السمان الياباني Coturnix japonica}

$$
\text { هدية كريم زوراب' و كمال علي صالح' }
$$

' فرع التشريح والأنسجة، كلية الطب البيطري، جامعة السليمانية،

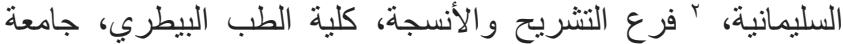
كركوك، كركوك، العراق اقن أن

الخلاصة

السمّان هو نموذج أساسي في أبحاث الطيور بسبب الأهمية

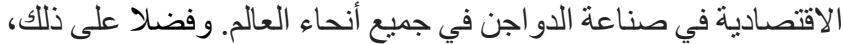

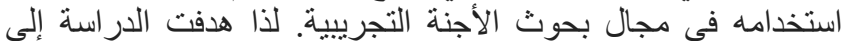

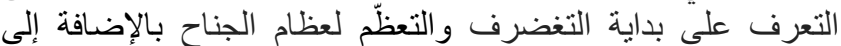

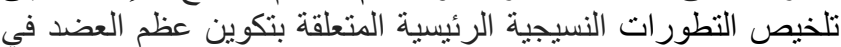

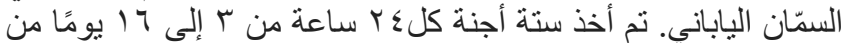

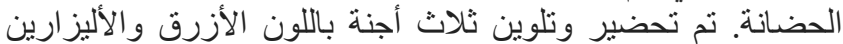
بالأحمر للغضاريف و العظام على التو الي وتم تحضير التاني الأجنة الثالاثنة

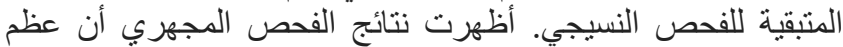

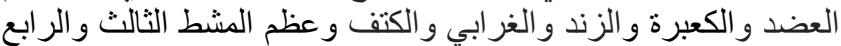

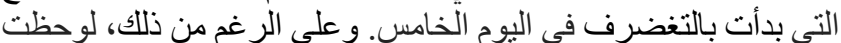
علامات التعظم الأولى في العضد و الكعبرة و الزند في اليوم التئ التامن. بينما بقي الأصبع الصغير غير متعظد حتى قبل التفقيس. أظهرت التهرم المراحل

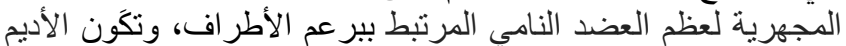

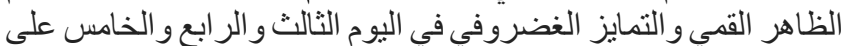

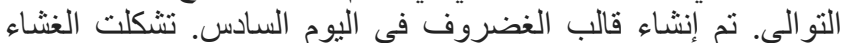

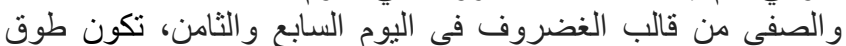

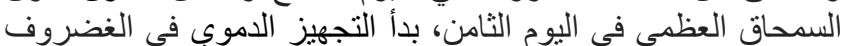

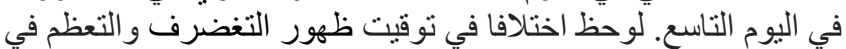

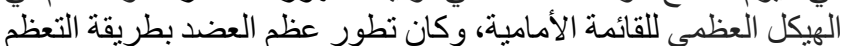

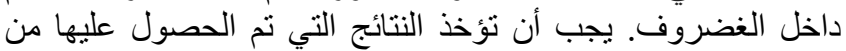

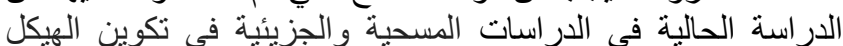

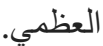

